Hyperhidrosis

\title{
Hoch wirksame Antitranspirante
}

— Schwitzen ist ein gesunder und notwendiger Vorgang des menschlichen Körpers und dient der Temperaturregelung. Aber starkes Schwitzen bringt mehr Flüssigkeitsverlust als Kühlungseffekt. Außerdem stören oft starker Schweißgeruch und große, dunkle „Wasserflecken" auf der Kleidung.

Das lässt sich durch spezielle Antitranspirante vermeiden. Darunter versteht man Mittel, die mittels eines dünnen Films aus Aluminiumsalzen die Schweißdrüsen verengen und die Schweißbildung auf ein normales Maß reduzieren. Unter der Marke Sweat-off werden seit 2006 nach der Rezeptur von Prof. Christian Raulin, Heidelberg und Greifswald, Rezepturen angeboten, die sich in der Praxis bei zahlreichen Anwendern bewährt haben.

Sweat-off ${ }^{\circledast}$ ist gut wirksam gegen unangenehme Schweißbildung und bei gesunder Haut gut verträglich - ob an Achseln, Armen, Beinen, Rücken, Händen und Füßen. Denn neben dem Wirkstoff Aluminiumchlorid unterstützen pflegende Substanzen wie hochgereinigtes Wasser und pflanzliche Zellulose die Verträglichkeit von Sweat-off ${ }^{\oplus}$-Antitranspiranten. Ohne Alkohol, Parfum, Farbstoffe und Konservierungsmittel ist das Mittel für Frauen und Männer gleichermaßen geeignet.

Während Deodorants den Schweißgeruch mit Alkohol und Parfüm überdecken, bieten Antitranspirante tatsächlichen Schutz davor, dass Schweiß und Geruch überhaupt entstehen: Sie redu- zieren die Schweißbildung auf ein natürliches Maß. Das bedeutet, dass die Haut zwar weiterhin etwas Schweiß bildet aber kaum spürbar und in deutlich geringerer Menge.

Die Folge ist, dass die wenige Feuchtigkeit schneller verdunsten kann und Bakterien ein Teil ihrer Nährstoffe entzogen wird, was schließlich die Geruchsbildung minimiert. Diese Wirkung ist nachhaltig über mehrere Tage spürbar.

Nach dem Auftragen lösen sich die Inhaltsstoffe des Antitranspirants auf der warmen Haut. Die enthaltenen Aluminiumsalze bilden einen Film, der sich über die Poren legt und die Schweißdrüsen an ihrer Oberseite verengt. Auf diese Weise wird an den behandelten Hautflächen die Schweißbildung deutlich reduziert. Uneffektiver Flüssigkeitsverlust ohne Temperaturregelung des Körpers wird vermieden.

\section{Sorgfältige Anwendung notwendig}

Die speziellen Rezepturen der Antitranspirante machen eine besondere Anwendung nötig: Sie müssen sie gezielt und dünn aufgetragen werden und über Nacht einwirken. Nur auf diese Weise ist der Langzeitschutz gegen Schweißbildung und Geruchsbelästigung gewährleistet. Insofern ist nicht allein der Wirkstoff Aluminiumchlorid entscheidend, sondern auch die richtige Balance der gesamten Inhaltsstoffe. Verbraucher sollten deshalb auf den Beipackzettel achten, der die besondere Anwendungsweise beschreibt.

\section{Hier steht eine Anzeige.}

